\title{
Modeling lipid accumulation in oleaginous fungi in chemostat cultures. II: Validation of the chemostat model using yeast culture data from literature
}

\author{
Petra Meeuwse • Johannes Tramper • \\ Arjen Rinzema
}

Received: 8 December 2010/ Accepted: 5 April 2011/Published online: 23 April 2011

(C) The Author(s) 2011. This article is published with open access at Springerlink.com

\begin{abstract}
A model that predicts cell growth, lipid accumulation and substrate consumption of oleaginous fungi in chemostat cultures (Meeuwse et al. in Bioproc Biosyst Eng. doi:10.1007/s00449-011-0545-8, 2011) was validated using 12 published data sets for chemostat cultures of oleaginous yeasts and one published data set for a polyhydroxyalkanoate accumulating bacterial species. The model could describe all data sets well with only minor modifications that do not affect the key assumptions, i.e. (1) oleaginous yeasts and fungi give the highest priority to C-source utilization for maintenance, second priority to growth and third priority to lipid accumulation, and (2) oleaginous yeasts and fungi have a growth rate independent maximum specific lipid production rate. The analysis of all data showed that the maximum specific lipid production rate is in most cases very close to the specific production rate of membrane and other functional lipids for cells growing at their maximum specific growth rate. The limiting factor suggested by Ykema et al. (in Biotechnol Bioeng 34:1268-1276, 1989), i.e. the maximum glucose uptake rate, did not give good predictions of the maximum lipid production rate.
\end{abstract}

Keywords Model validation - Chemostat - Oleaginous yeast $\cdot$ Lipid production rate

Electronic supplementary material The online version of this article (doi:10.1007/s00449-011-0546-7) contains supplementary material, which is available to authorized users.

P. Meeuwse $\cdot$ J. Tramper $\cdot$ A. Rinzema $(\square)$

Bioprocess Engineering, Wageningen University,

P.O. Box 8129, 6700 EV Wageningen, The Netherlands

e-mail: Arjen.rinzema@wur.nl

\section{Introduction}

In part I [1], we presented a mathematical model for lipid accumulation in oleaginous fungi growing in chemostat cultures. This model describes our chemostat cultures of $U$. isabellina growing on glucose as C-source and $\mathrm{NH}_{4}{ }^{+}$as $\mathrm{N}$-source well. In the current paper, we show that the model can also describe data obtained with oleaginous yeasts cultivated in chemostats using a large range of $\mathrm{C} / \mathrm{N}$ ratios and dilution rates, including the low dilution rates that could not be realized with $U$. isabellina. With the large set of data from literature, we also test hypotheses about the limiting factor for the specific lipid production rate. One of these hypotheses comes from the chemostat model published by Ykema et al. [2]. Finally, we show that our model for lipid accumulation can also predict accumulation of polyhydroxy-alkanoates (PHA), another carbon-based storage material.

\section{Model}

The model is based on the component mass balances, Pirt's law and two major assumptions [1]:

- The first priority of the fungus is to use the supplied C-source to satisfy its maintenance requirements, then to produce lipid-free biomass including functional lipids, and finally, only if there is still C-source available, to accumulate storage lipids.

- If sufficient $\mathrm{C}$-source is available, the specific lipid production rate will increase up to a maximum value $q_{L, \text { max }}$. This maximum specific lipid production rate is independent of the specific growth rate.

These assumptions lead to three different limitation regimes: 
Table 1 Literature data used to validate the model as is described in the text

\begin{tabular}{|c|c|c|c|c|c|c|c|}
\hline $\begin{array}{l}\text { Data } \\
\text { set } \\
\text { no. }\end{array}$ & References & Organisms & $\begin{array}{l}\text { Medium C-source/ } \\
\text { N-source }\end{array}$ & $\begin{array}{l}\text { Number of } \\
\text { datapoints }\end{array}$ & $\begin{array}{l}\mathrm{C} / \mathrm{N} \text { ratio } \\
(\mathrm{Cmol} / \mathrm{Nmol})\end{array}$ & $\begin{array}{l}\text { Dilution } \\
\text { rates }\left(\mathrm{h}^{-1}\right)\end{array}$ & $\begin{array}{l}\text { Reported } \\
\mu_{\max }\left(\mathrm{h}^{-1}\right)\end{array}$ \\
\hline \multicolumn{8}{|l|}{ Fungi } \\
\hline 1 & Hansson et al. [3] & Mucor rouxii ${ }^{\mathrm{c}}$ & Glucose $/ \mathrm{NH}_{4} \mathrm{Cl}+\mathrm{YE}$ & 15 & $11-29$ & $0.03-0.14$ & - \\
\hline 2 & Meeuwse et al. [1] & Umbelopsis isabellina & Glucose/($\left(\mathrm{NH}_{4}\right)_{2} \mathrm{SO}_{4}$ & $6+6$ & $16+20$ & $0.04-0.19$ & 0.23 \\
\hline 3 & Song et al. [4] & Mucor circinelloides & Glucose $/ \mathrm{NH}_{4} \mathrm{Cl}+\mathrm{YE}$ & 5 & 43 & $0.04-0.18$ & - \\
\hline \multicolumn{8}{|l|}{ Yeast } \\
\hline 4 & Alvarez et al. [5] & Rhodotorula glutinis & $\begin{array}{l}\text { Molasses (both C and } \\
\mathrm{N} \text { ) }\end{array}$ & 7 & $25-35$ & $0.04-0.1$ & - \\
\hline 5 & Brown et al. [6] & Candida curvata & Glucose/YE & $20^{\mathrm{d}}$ & 71 & $0.025-0.29$ & 0.305 \\
\hline 6 & Choi et al. [7] & Rhodotorula gracilis & $\begin{array}{l}\text { Glucose/ } \\
\qquad\left(\mathrm{NH}_{4}\right)_{2} \mathrm{SO}_{4}+\mathrm{YE}\end{array}$ & 6 & 53 & $0.02-0.09$ & - \\
\hline 7 & Evans and Ratledge [8] & Candida cruvata & Sugars ${ }^{\mathrm{e}} / \mathrm{NH}_{4} \mathrm{Cl}+\mathrm{YE}$ & $16+16^{\mathrm{f}}$ & $17+50-52^{g}$ & $0.02-0.3^{\mathrm{f}}$ & $0.3^{\mathrm{f}}$ \\
\hline 8 & Gill et al. [9] & Candida 107 & Glucose $/ \mathrm{NH}_{4} \mathrm{Cl}+\mathrm{YE}$ & $7+7$ & $6+26$ & $0.03-0.21$ & 0.21 \\
\hline 9 & $\begin{array}{l}\text { Hansson and Dostalek } \\
\text { [10] }\end{array}$ & Cryptococcus albidus & Glucose $/ \mathrm{NH}_{4} \mathrm{Cl}+\mathrm{YE}$ & $5+4$ & $10+58$ & $0.031-0.107$ & 0.11 \\
\hline 10 & Hassan et al. [11] & $\begin{array}{l}\text { Apiotrichum curvatum } \\
\text { UfaM3 } 3^{\mathrm{h}, \mathrm{i}}\end{array}$ & Glucose $/ \mathrm{NH}_{4} \mathrm{Cl}+\mathrm{YE}$ & 11 & 44 & $0.04-0.4$ & - \\
\hline 11 & $\begin{array}{l}\text { Papanikolaou and Aggelis } \\
\text { [12] }\end{array}$ & Yarrowia lipolytica & $\begin{array}{l}\text { Glycerol/ } \\
\qquad\left(\mathrm{NH}_{4}\right)_{2} \mathrm{SO}_{4}+\mathrm{YE}\end{array}$ & 5 & 147 & $0.03-0.13$ & 0.21 \\
\hline 12 & Ratledge and Hall [13] & Rhodotorula glutinis & Glucose $/ \mathrm{NH}_{4} \mathrm{Cl}+\mathrm{YE}$ & $5+4$ & $6+25$ & $0.02-0.1$ & 0.12 \\
\hline 13 & Ykema et al. [2] & 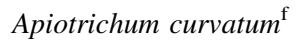 & Glucose $/ \mathrm{NH}_{4} \mathrm{Cl}+\mathrm{YE}$ & 11 & $7-68$ & 0.02 & 0.2 \\
\hline 14 & Yoon and Rhee [14] & Rhodotorula glutinis & $\begin{array}{l}\text { Glucose/ } \\
\qquad\left(\mathrm{NH}_{4}\right)_{2} \mathrm{SO}_{4}+\mathrm{YE}\end{array}$ & 7 & 62 & $0.01-0.1$ & 0.13 \\
\hline
\end{tabular}

${ }^{a} Y E$ yeast extract

${ }^{\mathrm{b}}$ When two $\mathrm{C} / \mathrm{N}$ ratios were used as is shown in the column to the right, the number of data points is mentioned for the two $\mathrm{C} / \mathrm{N}$ ratios separately

c Mainly present in a yeast-like form

d Including duplicates; nine different dilution rates were measured with 2-4 duplicates

e Glucose, sucrose, lactose and xylose, respectively. Ethanol was also used, but is not included in the modeling because it could not be modeled together with the sugars, and not enough data points are available to model it separately

${ }^{\mathrm{f}}$ Five data points per substrate were available, but at the highest dilution rate used, signs of washout were detected. These data points were therefore not used, and the highest dilution rate used was taken as $\mu_{\max }$

$\mathrm{g}$ The same concentrations in grams were used for all sugars, which leads to different $\mathrm{C} / \mathrm{N}$ ratios in moles because of different molar weights

${ }^{\mathrm{h}}$ Mutant blocked in $\Delta^{9}$-desaturase

${ }^{\mathrm{i}}$ A. curvatum is currently also called Candida curvata

- Single nitrogen limitation, where the $\mathrm{N}$-source limits the lipid-free biomass formation and the specific lipid production rate has its maximum value;

- Dual limitation of $\mathrm{C}$-source and $\mathrm{N}$-source, where the $\mathrm{N}$-source limits the lipid-free biomass formation and the $\mathrm{C}$-source limits the lipid production;

- Single carbon limitation, where the C-source limits the lipid-free biomass formation and only membrane lipids are produced.

The equations used in the model are shown in Table 1 of part I [1]. For the calculations in this paper, we used molecular weights of $25 \mathrm{~g} \mathrm{Cmol}^{-1}$ for lipid-free biomass and $15.7 \mathrm{~g} \mathrm{Cmol}^{-1}$ for lipids. A list of symbols can be found in part I.

\section{Results and discussion}

Table 1 shows an overview of chemostat cultures with more than four dilution rates or $\mathrm{C} / \mathrm{N}$ ratios found in literature. In most studies one or two constant $\mathrm{C} / \mathrm{N}$ ratios and various dilution rates were used. In most studies, a high $\mathrm{C} / \mathrm{N}$ ratio in the feed $(>20 \mathrm{Cmol} / \mathrm{Nmol})$ was used to promote lipid accumulation. Some studies also included a low $\mathrm{C} / \mathrm{N}$ ratio, which does not lead to lipid production in most cases.

Model parameters were determined for all data sets in Table 1, in most cases using all data within a set, independent of the $\mathrm{C} / \mathrm{N}$ ratio or dilution rate. Because of the large number of studies used, we will not describe all studies separately. We will discuss the fitting procedure 
and the predictions for all studies in general and point out some exceptions. Graphs showing the measured data points together with the model predictions for all studies are shown in the electronic supplementary material; parity plots and an example of measured data when compared with model predictions are included this article.

\section{Chemostat cultures with filamentous fungi}

The results from submerged chemostat studies with oleaginous fungi are hardly described in the literature: we only found three papers on this topic. The first (Data set 1) uses the filamentous fungus Mucor rouxii [3]. This fungus has a filamentous and a yeast-like morphology, and the yeast-like form was observed during most of the experiments. The filamentous form of Mucor rouxii is able to accumulate lipids up to $30 \% w / w$ [15], but in the yeast-like form $<10 \%$ $w / w$ lipids was found, even in the presence of residual glucose. Therefore, Data set 1 was not suitable to fit the model. In our studies with $U$. isabellina (Data set 2 [1]) we also observed that the filamentous fungus transformed to a yeast-like morphology when it was cultivated at a high dilution rate and exposed to the shear forces of the stirrer for at least 7 days. This yeast-like form also did not accumulate lipids and was not included in the model validation. Data set 2 has been discussed extensively in part I [1] and will therefore not be discussed here. Data set 3 uses Mucor circinelloides [4] and will be discussed together with the yeast cultures. Kendrick and Ratledge [16] used the fungus Entomophtora exitalis in chemostat culture, but only used one $\mathrm{C} / \mathrm{N}$ ratio and dilution rate. As our model needs at least four data points for the determination of parameter values, this data set was not used.

\section{Chemostat cultures with oleaginous yeasts}

All studies in Table 1 report total biomass concentrations and lipid concentrations or lipid fractions in the cells, but they do not always report all substrate concentrations required to find the model parameters. For Data sets 2, 4-6 and $8-11$, the $\mathrm{C}$-source and $\mathrm{N}$-source concentrations are reported, or the limiting (=depleted) substrate is indicated and the concentration of the non-limiting substrate is reported. For Data sets 3, 7 and 12-14, however, one or both substrate concentrations are not reported. Therefore, these data sets could not be completely described by the model, as will be discussed later. None of the studies reports $\mathrm{CO}_{2}$ production or $\mathrm{O}_{2}$ consumption. Data set 13 was obtained under non-steady state conditions in a continuous culture with a changing $\mathrm{C}$-source concentration in the feed. To describe this data set, changes in time have to be taken into consideration, which makes the model and the fitting procedure for this data set different from the other data sets. Therefore, we decided not to use this data set for the validation of the model; however, we will discuss non-steady state situations later in this article.

\section{Determination of parameter values}

To describe the data sets with our model, values have to be found for the basal (membrane) lipid fraction in the cells $\left(f_{L 0}\right)$, the yield of lipid-free biomass on N-source $\left(Y_{X N}\right)$, the yield of lipid-free biomass on C-source $\left(Y_{X S}\right)$, the yield of lipids on C-source $\left(Y_{L S}\right)$, the maintenance coefficient $\left(m_{\mathrm{S}}\right)$ and the maximum specific lipid production rate $\left(q_{L, \max }\right)$. The approach used to determine these parameters has been described in detail in part I [1]. All parameter values found are shown in Table 2.

\section{Basal lipid content of the cells $\left(f_{L O}\right)$}

If available, we used the reported lipid fraction in the C-limitation regime as the basal lipid content of the cells. However, not all studies report results in this regime. For these studies, we used either an estimated value of $10 \% \mathrm{w} /$ $w=0.015 \mathrm{Cmol} \mathrm{Cmol}^{-1}$, which is the average measured value found in literature, or the lowest reported lipid fraction if this was below $10 \% \mathrm{w} / \mathrm{w}$ (see Table 2).

\section{Yield of lipid-free biomass on $\mathrm{N}$-source}

As was discussed before in part I [1], the yield of lipid-free biomass on N-source $\left(Y_{X N}\right)$ can be calculated with the following equation:

$Y_{X N}=\frac{C_{X}}{C_{\mathrm{Nin}}-C_{N}}$.

If present, yeast extract (YE) was taken into consideration as $\mathrm{N}$-source; it was assumed to contain $10 \% \mathrm{~N} w / w$, unless another fraction was reported in the study.

For data sets with a $\mathrm{C} / \mathrm{N}$ ratio $\leq 20 \mathrm{Cmol} / \mathrm{Nmol}$, the overall $Y_{X N}$ could be calculated by taking the average value for all data points. For data sets with a $\mathrm{C} / \mathrm{N}$ ratio $>20 \mathrm{Cmol} /$ Nmol, however, $Y_{X N}$ did not have a constant value, but depended on the dilution rate:

$Y_{X N}=a-b D$.

This linear dependence is shown in Fig. 1 for Data sets 8 and 10. In Data set 8 , two different $\mathrm{C} / \mathrm{N}$ ratios were used: $26 \mathrm{Cmol} / \mathrm{Nmol}(8 \mathrm{a})$ and $6 \mathrm{Cmol} / \mathrm{Nmol}(8 \mathrm{~b})$, with the same yeast strain and substrates. In Data set 10 , one $\mathrm{C} / \mathrm{N}$ ratio (44 Cmol/Nmol) was used. Figure 1 shows clearly that a high $\mathrm{C} / \mathrm{N}$ ratio (Data sets $8 \mathrm{a}$ and 10 ) gives a linear decrease in the yield with increasing dilution rate, while a low $\mathrm{C} / \mathrm{N}$ 
Table 2 Model parameters found for the literature data

\begin{tabular}{|c|c|c|c|c|c|c|}
\hline $\begin{array}{l}\text { Data } \\
\text { set no. }\end{array}$ & $\begin{array}{l}f_{L 0} \\
\left(\mathrm{Cmol} \mathrm{Cmol}^{-1}\right)\end{array}$ & $\begin{array}{l}Y_{X N}^{\mathrm{a}} \pm \mathrm{SD} \\
\left(\mathrm{Cmol} \mathrm{Nmol}^{-1}\right)\end{array}$ & $\begin{array}{l}q_{L, \max } \pm \mathrm{SD} \\
\left(\mathrm{Cmol} \mathrm{Cmol}^{-1} \mathrm{~h}^{-1}\right)\end{array}$ & $\begin{array}{l}Y_{X S} \pm \mathrm{SD} \\
\left(\mathrm{Cmol} \mathrm{Cmol}^{-1}\right)\end{array}$ & $\begin{array}{l}Y_{L S} \pm \mathrm{SD} \\
\left(\mathrm{Cmol} \mathrm{Cmol}^{-1}\right)\end{array}$ & $\begin{array}{l}m_{\mathrm{S}} \pm \mathrm{SD} \\
\left(\mathrm{Cmol} \mathrm{Cmol}^{-1} \mathrm{~h}^{-1}\right)\end{array}$ \\
\hline 2 & 0.079 & $6.1 \pm 0.7$ & $0.023 \pm 0.005$ & $0.92 \pm 0.10$ & $0.59^{\mathrm{b}}$ & $0.05 \pm 0.01$ \\
\hline 3 & 0.15 & $(12.1 \pm 0.7)-(37 \pm 5) * \mathrm{D}$ & $0.032 \pm 0.007^{\mathrm{c}}$ & $\mathrm{ND}^{\mathrm{d}}$ & $\mathrm{ND}^{\mathrm{d}}$ & $\mathrm{ND}^{\mathrm{d}}$ \\
\hline 4 & 0.15 & $(13.7 \pm 1.4)-(71 \pm 23) * \mathrm{D}^{\mathrm{e}}$ & $0.039 \pm 0.006$ & $0.56 \pm 0.07$ & $0.99 \pm 0.36$ & $0^{\mathrm{b}}$ \\
\hline 5 & 0.12 & $(15.3 \pm 0.6)-(41 \pm 4) * \mathrm{D}$ & $0.040 \pm 0.008$ & $0.86 \pm 0.11$ & $0.65 \pm 0.27$ & $0^{\mathrm{b}}$ \\
\hline 6 & 0.15 & $(8.5 \pm 0.7)-(70 \pm 15)^{*} \mathrm{D}$ & $0.027 \pm 0.006$ & $0.25 \pm 0.02$ & $0.59^{\mathrm{b}}$ & $0^{\mathrm{b}}$ \\
\hline $\begin{array}{l}7 a^{f} \\
7 b^{f}\end{array}$ & 0.19 & $\begin{array}{l}(22 \pm 1)-(84 \pm 11) * \mathrm{D} \\
\mathrm{ND}^{\mathrm{d}}\end{array}$ & $0.037 \pm 0.010^{\mathrm{c}, \mathrm{g}}$ & $0.55 \pm 0.02^{\mathrm{g}, \mathrm{h}}$ & $0.59^{\mathrm{b}}$ & $0^{\mathrm{b}}$ \\
\hline $\begin{array}{l}8 a^{f} \\
8 b^{f}\end{array}$ & 0.15 & $\begin{array}{l}(13.8 \pm 0.7)-(38 \pm 6) * \mathrm{D} \\
5.8 \pm 0.3\end{array}$ & $0.069 \pm 0.009$ & $0.62 \pm 0.03$ & $0.88 \pm 0.14$ & $0^{\mathrm{b}}$ \\
\hline $\begin{array}{l}9 a^{f} \\
9 b^{f}\end{array}$ & 0.15 & $\begin{array}{l}(18 \pm 2)-(83 \pm 30) * \mathrm{D} \\
6.4 \pm 0.5\end{array}$ & $\begin{array}{l}0.041 \pm 0.004 \\
0.032 \pm 0.002\end{array}$ & $0.75 \pm 0.05$ & $0.47 \pm 0.04$ & $0^{\mathrm{b}}$ \\
\hline 10 & 0.12 & $(16.5 \pm 0.4)-(34 \pm 2) * \mathrm{D}$ & $0.065 \pm 0.015$ & $0.73 \pm 0.04$ & $0.88 \pm 0.18$ & $0^{\mathrm{b}}$ \\
\hline 11 & 0.12 & $(16.9 \pm 0.8)-(37 \pm 10)^{*} \mathrm{D}$ & $0.030 \pm 0.013$ & $0.16 \pm 0.01$ & $0.97 \pm 0.34$ & $0^{\mathrm{b}}$ \\
\hline $\begin{array}{l}12 a^{f} \\
12 b^{f}\end{array}$ & 0.21 & $\begin{array}{l}(9.8 \pm 0.4)-(62 \pm 6) * \mathrm{D} \\
\mathrm{ND}^{\mathrm{d}}\end{array}$ & $0.031 \pm 0.004^{\mathrm{c}}$ & $0.56 \pm 0.04^{h}$ & $0.77 \pm 0.41^{\mathrm{h}}$ & $0^{\mathrm{b}}$ \\
\hline 14 & 0.15 & $(8.1 \pm 0.4)-(60 \pm 8) * \mathrm{D}$ & $0.028 \pm 0.006^{\mathrm{c}}$ & $\mathrm{ND}^{\mathrm{d}}$ & $\mathrm{ND}^{\mathrm{d}}$ & $\mathrm{ND}^{\mathrm{d}}$ \\
\hline
\end{tabular}

${ }^{a}$ Yield of lipid-free biomass on $\mathrm{N}$-source as a function of the dilution rate $\mathrm{D}\left(r^{2}>0.80\right.$ unless stated otherwise) or as a constant value (see text)

b Estimated value

${ }^{\mathrm{c}}$ Because no $\mathrm{C}$-source concentration was reported, only data points where no C-source limitation $\left(C_{\mathrm{S}}>0\right)$ could reasonably be assumed (see text), were used to determine these parameter values

${ }^{\mathrm{d}}$ Not determined because substrate concentrations were not reported

e $r^{2}=0.66$

${ }^{\mathrm{f}}$ Data set a contains data points from $\mathrm{N}$-limited culture (high $\mathrm{C} / \mathrm{N}$ ratio), data set $\mathrm{b}$ contains data points from $\mathrm{C}$-limited culture (low $\mathrm{C} / \mathrm{N}$ ratio)

$\mathrm{g}$ Differences in parameter values for the different substrates were not significant and we determined one value for all sugars

${ }^{\mathrm{h}}$ Because no $\mathrm{C}$-source concentration was reported, only data points where a C-source limitation $\left(C_{\mathrm{S}}=0\right)$ could reasonably be assumed (see text) were used to determine these parameter values

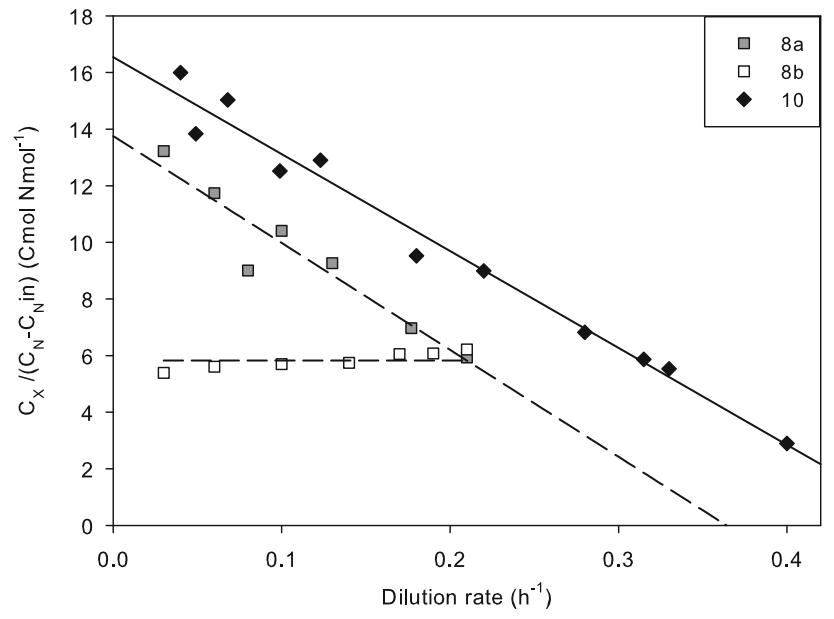

Fig. 1 The yield of lipid-free biomass on N-source as a function of the dilution rate for Data sets $8 \mathrm{a}(\mathrm{C} / \mathrm{N}=26 \mathrm{Cmol} / \mathrm{Nmol}), 8 \mathrm{~b}$ $(\mathrm{C} / \mathrm{N}=6 \mathrm{Cmol} / \mathrm{Nmol})$ and $10(\mathrm{C} / \mathrm{N}=44 \mathrm{Cmol} / \mathrm{Nmol})$

ratio (Data set $8 b$ ) does not. This is also the case for the other data sets; the values or equations for $Y_{X N}$ are shown in Table 2. The dependency of the yield of lipid-free biomass on the dilution rate at a high $\mathrm{C} / \mathrm{N}$ ratio $(\mathrm{C} / \mathrm{N}>20 \mathrm{Cmol} /$ $\mathrm{Nmol}$ ) was not reported in the original publications. As far as we know, this is the first time that this linear dependency is reported. We assume that this change in yield is caused by accumulation of another carbon-based storage material than lipids, because it only appears at high $\mathrm{C} / \mathrm{N}$ ratios, when the $\mathrm{C}$-source is in abundance. In this respect, it is similar to the accumulation of lipids, which also appears at high $\mathrm{C} / \mathrm{N}$ ratios and increases with decreasing dilution rate. The accumulation of lipid precursor molecules has been reported before [2], but a relation with the dilution rate was not found. None of the studies in Table 1 reported another storage material or (changes in) the element composition of the biomass.

The values found for the yield of lipid-free biomass on N-source $\left(Y_{X N}\right)$ reported in Table 2 can be used to predict the lipid-free biomass concentration $\left(C_{X}\right)$ during N-limitation (Eq. 12, Table 1 in part I) and the $\mathrm{N}$-source concentration in the fermenter $\left(C_{\mathrm{N}}\right)$ during single $\mathrm{C}$-limitation (Eq. 11, Table 1 in part I). Figure $2 \mathrm{a}$ and $\mathrm{b}$ shows two parity plots of the modeled versus the measured lipid-free 
biomass concentration, calculated with a constant value for $Y_{X N}$ (Eq. 22, Fig. 2a) and with a dilution rate dependent value for $Y_{X N}$ (Eq. 27, Fig. 2b), respectively. Figure 2b shows a much better correlation between measured and modeled values than Fig. 2a, indicating that Eq. 27 gives a better fit than a constant value for $Y_{X N}$ when $\mathrm{C} / \mathrm{N}>20 \mathrm{Cmol} / \mathrm{Nmol}$ (see Table 2). So, the reason for the linear relation between the yield of lipid-free biomass on N-source $\left(Y_{X N}\right)$ and the dilution rate $(D)$ is not known, Eq. 27 is used in the fitting procedure because it describes the data very well.

Only very few studies applied C-limitation and reported values for the $\mathrm{N}$-source concentration in the fermenter $\left(C_{\mathrm{N}}\right)$. Reported $\mathrm{N}$-source concentrations are compared with the predicted values in Fig. 2c. The few data points that are depicted in this parity plot are close to the correlation line, so from this plot and Fig. 2b we can conclude that the values found for $Y_{X N}$ are suitable for use in the model.

\section{Maximum specific lipid production rate}

Because we assume that the specific lipid production rate is constant when the $\mathrm{C}$-source is not limiting, the value for the maximum specific lipid production rate $\left(q_{L, \max }\right)$ was calculated by taking the average specific lipid production rate for all data points with $C_{\mathrm{N}}=0$ and $C_{\mathrm{S}}>0$. For Data sets 3, 7, 12 and 14, the C-source concentration $\left(C_{\mathrm{S}}\right)$ was not reported, but the occurrence of N-limitation $\left(C_{\mathrm{N}}=0\right)$ was reported. Therefore, for the data points with $C_{\mathrm{N}}=0$, we did not know if the cells were subjected to single N-limitation $\left(C_{\mathrm{S}}>0\right)$ or to dual limitation $\left(C_{\mathrm{S}}=0\right)$. Because single N-limitation usually occurs at a higher dilution rate than dual limitation, we calculated the maximum specific lipid production rate using only data points with N-limitation and a high dilution rate for which the specific lipid production rate appeared to be constant.

All values for the maximum specific lipid production rate $\left(q_{L, \text { max }}\right)$ are shown in Table 2 . The standard deviation for most values is quite small, indicating that the value of the specific lipid production rate was indeed constant for the used data points. No dependency on the dilution rate or the $\mathrm{C} / \mathrm{N}$ ratio was found. The maximum specific lipid production rate $\left(q_{L, \max }\right)$ predicts the lipid concentration in the fermenter and the lipid fraction in the cells when the $\mathrm{C}$-source is in abundance (Eq. 15, Table 1 in part I). The parity plot in Fig. 2d shows that the lipid fraction in the cells is predicted very well.

Data set 9 has two values for the maximum specific lipid production rate $\left(q_{L, \text { max }}\right)$, depending on the limiting component (N-limitation or C-limitation). This yeast is an exception to the rule that cells have a constant lipid fraction in the cells during single C-limitation. For an unknown reason, this strain also produces lipids at a constant rate under C-limitation, i.e. it gives priority to lipid production at the expense of lipid-free biomass production. This has been described before by Boulton and Ratledge [17]. To model this phenomenon, we have to alter the model slightly. In the model described in part I, the specific lipid production rate during single $\mathrm{C}$-limitation is proportional to the specific growth rate:

$q_{L, \min }=\frac{f_{L 0}}{1-f_{L 0}} D$

For Data set 9, the specific lipid production rate is constant and independent of the specific growth rate:

$q_{L, \min }=$ constant

The constant minimum specific lipid production rate $\left(q_{L, \min }\right)$ for Data set 9 was calculated by taking the average of the specific lipid production rates during single C-limitation. This allowed accurate modeling of this data set, as shown in Fig. 2d.

Yields of lipid-free biomass and lipids on C-source and maintenance coefficient

The specific substrate consumption rate is divided into three parts: lipid-free biomass production, lipid production and maintenance:

$q_{\mathrm{S}}=\frac{D\left(C_{\mathrm{Sin}}-C_{\mathrm{S}}\right)}{C_{X}}=\frac{D}{Y_{X S}}+\frac{q_{L}}{Y_{L S}}+m_{\mathrm{S}}$

Multiple linear regression analysis using Eq. 23 was applied to find $Y_{X S}, Y_{L S}$ and $m_{\mathrm{S}}$. However, for none of the data sets from literature, this gave a reliable value for the maintenance coefficient. In all cases, the obtained value for $m_{\mathrm{S}}$ was negative or had such a large standard deviation that it was not significantly different from zero. Therefore, the maintenance coefficient $\left(m_{\mathrm{S}}\right)$ was set to zero and values for $Y_{X S}$ and $Y_{L S}$ were obtained (Table 2). For Data sets 2, 6 and 7, a theoretical value of $Y_{L S}=0.59 \mathrm{Cmol} \mathrm{Cmol}^{-1}$ was used as was published by Ratledge [18]. The fitting of Data set 2 was discussed extensively in part I. Fitting of $Y_{L S}$ for Data set 6 and 7 gave unrealistic values of $Y_{L S} \pm \mathrm{SD}=9 \times 10^{3}$ $\pm 6 \times 10^{7} \mathrm{Cmol} \mathrm{Cmol}^{-1}$ and $Y_{L S} \pm \mathrm{SD}=7 \times 10^{3} \pm$ $9 \times 10^{7} \mathrm{Cmol} \mathrm{Cmol}^{-1}$, respectively, and therefore we replaced $Y_{L S}$ with the literature value of $0.59 \mathrm{Cmol} \mathrm{Cmol}^{-1}$.

All values found for the yield of lipid-free biomass on C-source $\left(Y_{X S}\right)$ are in the expected range when the inaccuracy is taken into consideration. Only the value for Data set 2 is very high; this was discussed in detail in part I. Data sets 6 and 11 have a very low value for $Y_{X S}$. This could be 

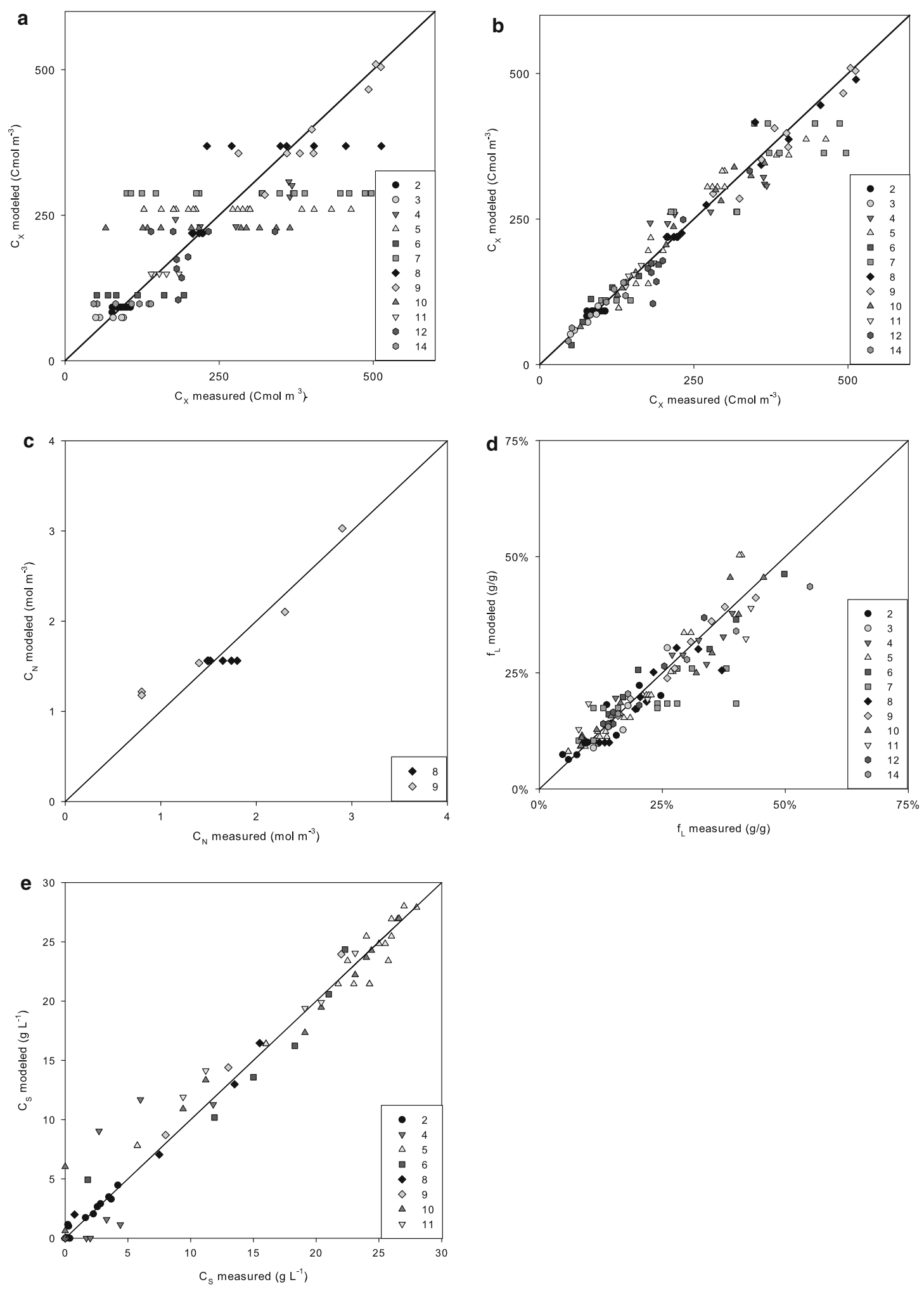

Fig. 2 Parity plots for the data sets described in Table 1. a Lipid-free biomass, with the yield of lipid-free biomass on $\mathrm{N}$-source $\left(Y_{X N}\right)$ calculated according to Eq. 22. b Lipid-free biomass, with the yield of lipid-free biomass on $\mathrm{N}$-source $\left(Y_{X N}\right)$ calculated according to Eq. 27 for data points with the $\mathrm{C} / \mathrm{N}$ ratio in the feed $>20 \mathrm{Cmol} / \mathrm{Nmol}$ and calculated according to Eq. 22 for data points with the $\mathrm{C} / \mathrm{N}$ ratio in the

feed $<20 \mathrm{Cmol} / \mathrm{Nmol}$. c Nitrogen source concentration in the fermenter, with the yield of lipid-free biomass on $\mathrm{N}$-source $\left(Y_{X N}\right)$ calculated according to Eq. 22. d Lipid fraction in the cells. e C-source concentration in the fermenter. For Data set 5 , all values were divided by 2 to bring them in the same range as the other data points 
caused by the use of C-source for the production of extra products that were not measured. Data set 11 does report production of small amounts of citrate, but taking this product into consideration did not increase the value for $Y_{X S}$. Therefore, other by-products may have been present. The values found for $Y_{L S}$ are generally above the theoretical value of $0.59 \mathrm{Cmol} \mathrm{Cmol}^{-1}$, but several values are not very accurate as is indicated by a large standard deviation, so no conclusions can be drawn here.

Because all data sets lack $\mathrm{CO}_{2}$-production data, the carbon balance and therefore the assumption that no other products besides biomass, lipids and $\mathrm{CO}_{2}$ were formed, could not be checked. The parameter values found are based on this assumption and are, therefore, only valid if the model is not extended with by-product formation.

For most data points, the parameters $Y_{X S}, Y_{L S}$ and $m_{\mathrm{S}}$ predict the concentration of $\mathrm{C}$-source in the fermenter well (Eq. 10, Table 1 in part I); a parity plot is shown in Fig. 2e. For some data points that experience C-limitation, the parameters $Y_{X S}, Y_{L S}$ and $m_{\mathrm{S}}$ are needed to predict the specific lipid production rate (Eq. 16, Table 1 in part I) or the lipid-free biomass concentration (Eq. 13, Table 1 in part I), as was explained in part I. Parity plots for these variables were already shown in Fig. $2 b$ and d.

\section{Fit of the model to the data sets}

All parity plots in Fig. 2b-e show that the model gives a good fit for all data sets with the parameter values from Table 2. So far, we have not been able to find chemostat results for oleaginous yeast or fungi in literature that cannot be described with the model, unless there was a clear reason for it, as was the case with Data set 1.

Figure 3 illustrates that the model predicts the trends of the different concentrations as a function of the dilution rate very well. Similar graphs for all data sets are shown in the electronic supplementary material.

\section{Comparison with previously published model}

A model for growth and lipid production in continuous culture was published before by Ykema et al. [2]. This model is similar to our model; the major differences are

- carbohydrates stored in the cells are included as an extra product

- the maximum specific lipid production rate of the cells is not constant, but is given by the difference between their maximum specific glucose uptake rate $\left(\frac{\mu_{\max }}{Y_{X S}}+\frac{q_{L \text { min }}}{Y_{L S}}+m_{S}\right)$ and their actual specific glucose requirement for growth and maintenance $\left(\frac{D}{Y_{X S}}+m_{S}\right)$

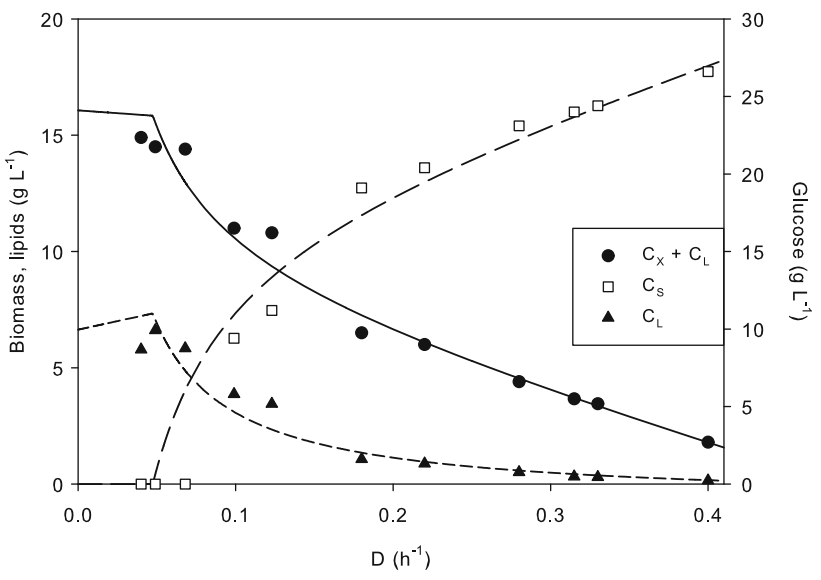

Fig. 3 Experimental data (symbols) with fitted model (lines) for total biomass concentration $\left(C_{X}+C_{\mathrm{L}}, r^{2}=0.97\right)$, carbon source left in medium $\left(C_{\mathrm{S}}, r^{2}=0.97\right)$ and lipid concentration $\left(C_{\mathrm{L}}, r^{2}=0.93\right)$. Data set 10, from Hassan et al. [11], Table 2

Ykema et al. [2] validated their model using a continuous culture of Apiotrichum curvatum with a constant dilution rate and a changing $\mathrm{C} / \mathrm{N}$ ratio of the feed. As the change in $\mathrm{C} / \mathrm{N}$ ratio was quite fast, this continuous culture was not in steady state, while all mass balances used in the model require steady state to be valid. Furthermore, a theoretical glucose concentration in the reactor was used for validation instead of the glucose concentration in the feed. This theoretical glucose concentration in the reactor was calculated assuming no consumption of glucose in the reactor, but only supply and washout by the ingoing and outgoing flow, respectively. Because in reality there is consumption in the reactor, the outgoing flow will contain less glucose than is assumed using this theoretical glucose concentration in the reactor. This leads to an underestimation of the glucose consumption. We doubt that this model was properly validated; this triggered us to develop our model and to check if the assumptions used in the model of Ykema et al. [2] are indeed valid.

Ykema's [2] assumption that the maximum specific glucose uptake rate is limiting for lipid production leads to the following equation for the maximum specific lipid production rate:

$$
\left.\begin{array}{rl}
D & =\mu_{\max }: q_{S, \text { max }}=\frac{\mu_{\max }}{Y_{X S}}+\frac{q_{L, \min }}{Y_{L S}}+m_{S} \\
D & <\mu_{\max }: q_{S, \max }=\frac{D}{Y_{X S}}+\frac{q_{L, \max }}{Y_{L S}}+m_{S}
\end{array}\right\} q_{L, \text { max }}
$$

To check Ykema's [2] hypothesis, we used this equation to calculate the maximum specific lipid production rate for the data sets in Table 1, instead of the constant value in Table 2. Parity plots for the lipid content of the cells and 
the concentration of $\mathrm{C}$-source in the fermenter obtained with Eq. 29 are shown in Fig. 4. For Data sets 4, 6 and 10, no $\mu_{\max }$ was reported. For these data sets, we used the highest reported dilution rate without washout in Eq. 29; these values are shown in Fig. 4. Data sets 3 and 14 are not shown in the figure because insufficient parameter values are available to estimate the maximum specific lipid production rate with Eq. 29 (see Table 2). Figure 4 shows that in most cases, the lipid fraction in the cells is overestimated with Eq. 29, and therefore the residual $\mathrm{C}$-source concentration is underestimated. Comparison of Fig. 2d and e with Fig. $4 \mathrm{a}$ and $\mathrm{b}$ leads to the conclusion that a constant value for the maximum specific lipid production rate gives a much better correlation between the model and the experimental data. This shows that Ykema's [2] assumption that the maximum specific glucose uptake rate can be used to predict lipid production in chemostat is not correct.

\section{Regulation of the maximum lipid production rate}

Although the metabolic pathway and the enzymes involved in lipid production in oleaginous yeast and fungi are known [19], nothing is known about the regulation of the maximum specific lipid production rate. We showed before that the maximum glucose uptake rate, as used in the model of Ykema et al. [2], is not limiting for the maximum specific lipid production rate. Therefore, we propose another hypothesis.

Our hypothesis is that the enzyme activity of the rate limiting step in the lipid synthesis pathway determines the maximum specific lipid production rate. We assume that in chemostat the lipid accumulation pathway is not switched on by nitrogen shortage as was found by Ratledge and Wynn [19] in batch, because nitrogen source is constantly supplied in chemostat. Therefore, we assume that only the enzymes needed for membrane lipid production are available for lipid production, and that no extra enzymes are produced. The membrane lipid synthesizing enzymes reach their maximum activity at the maximum specific growth rate, when the highest specific membrane lipid production rate is needed. This leads to the following equation for the maximum specific lipid production rate:

$q_{L, \max }=\frac{f_{L 0}}{1-f_{L 0}} \mu_{\max }$

Figure 5 compares the maximum specific lipid production rates found with this equation to measured values. Data set 9 is not included because $f_{L 0}$ does not have a constant value for this data set. For Data sets 3, 4, 6 and $10 \mu_{\max }$ was not reported. In these cases, we used the
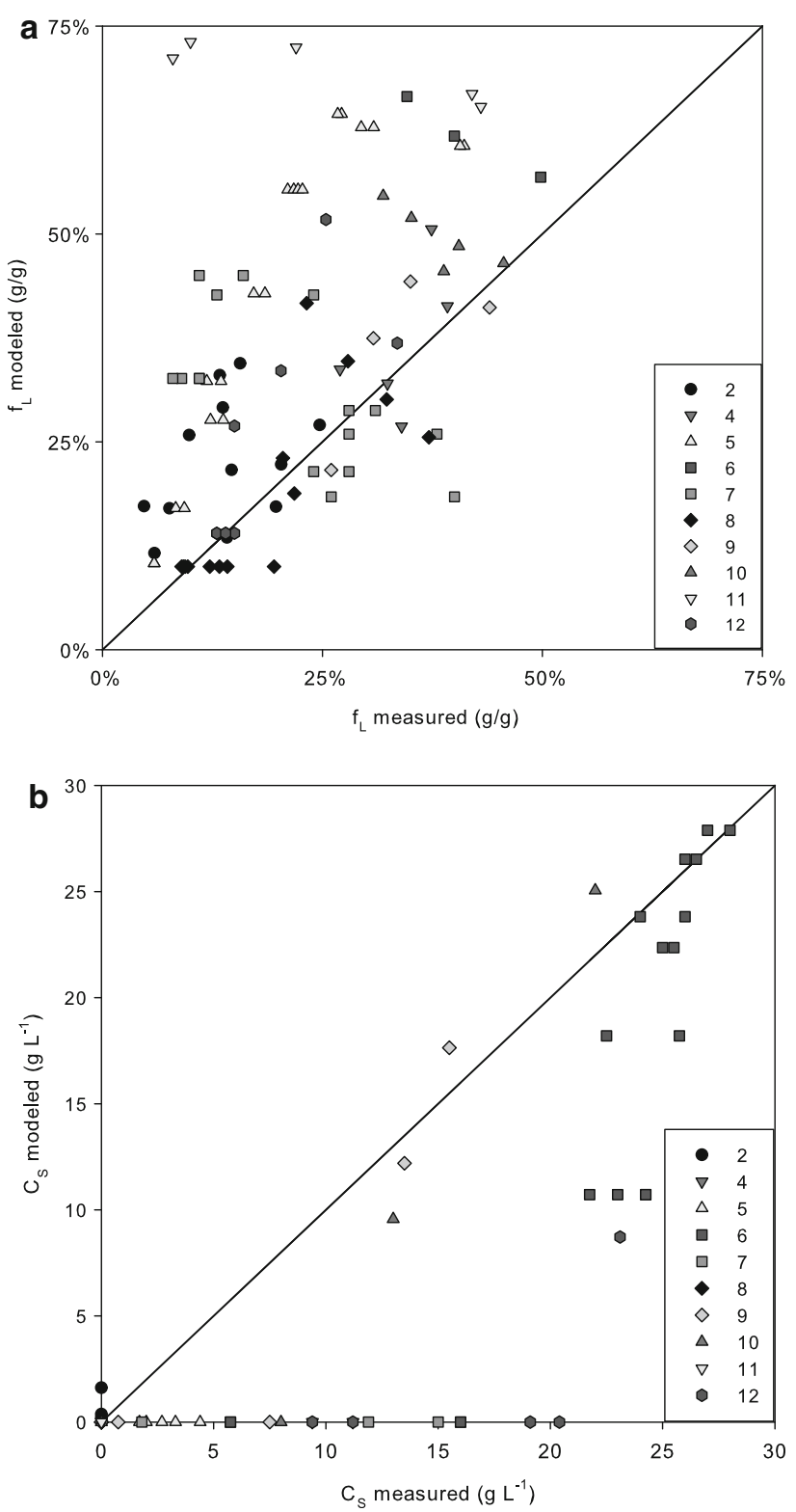

Fig. 4 Parity plots of the lipid fraction in the cells (a) and the C-source concentration in the fermenter (b), calculated with Eq. 29 instead of with a constant maximum specific lipid production rate. Numbers of data sets: see Table 1

highest applied dilution rate (without washout) as $\mu_{\max }$ value, as is indicated by arrows in the figure. Figure 5 shows that all data sets except Data sets 7 and 8 are close to or just below the correlation line. This means that indeed for most data sets, the maximum specific lipid production rate is equal to or slightly higher than the specific lipid production rate in cells growing at $\mu_{\max }$. This means that we cannot reject our hypothesis. Further research including enzyme activity measurements can give more insight in this matter. 


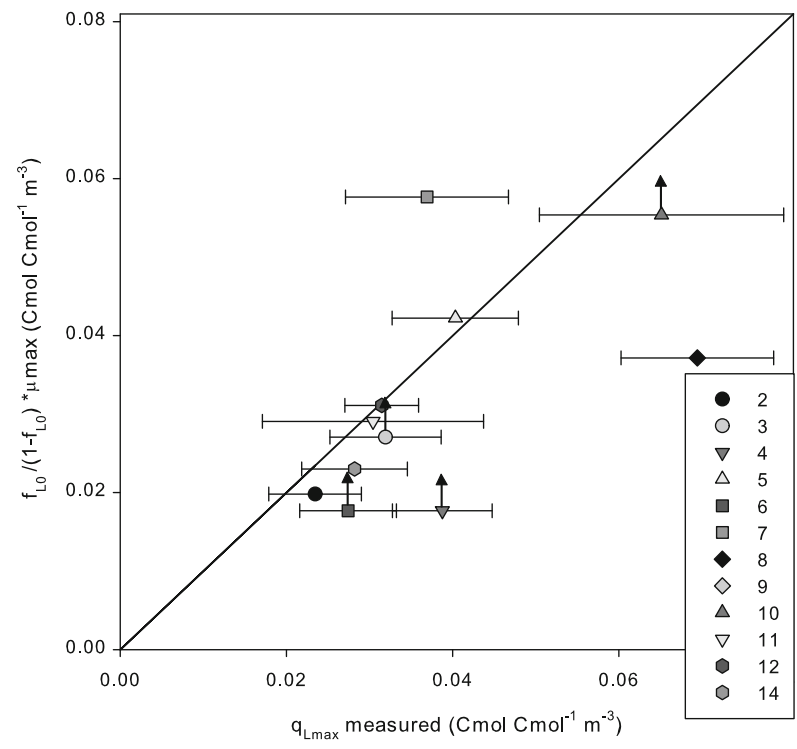

Fig. 5 Parity plot of the maximum specific lipid production rate during $\mathrm{C}$-limitation versus the measured average lipid production rate during N-limitation, calculated with Eq. 30 . The arrows indicate that the maximum specific growth rate was not given and, therefore, the maximum applied dilution rate was used, which means that the calculated value can be too low. Numbers of data sets: see Table 1

\section{Broader use of the model}

Some microorganisms store other forms of carbon source in their cells instead of lipids. A well known storage product is polyhydroxy-alkanoate (PHA). We used our model to describe PHA storage in Pseudomonas oleovorans from the data set of Durner et al. [20], which contains 50 data points for 5 different dilution rates and several $\mathrm{C} / \mathrm{N}$ ratios. A summary of the properties of the data set and the parameter values found for this data set is shown in Table 3. The large number of data points provided enough information to fit all parameter values. Figure 6 shows the data points together with the model predictions. All five graphs were obtained with the same parameter values. The model describes all data well for a wide range of combinations of dilution rate and feed $\mathrm{C} / \mathrm{N}$ ratio, although the prediction of C-source consumption is less good than the prediction of biomass and PHA concentrations. We conclude that our model can also describe PHA production well.

\section{Use of the model for non-steady state conditions}

When developing the model, we assumed steady state in the culture and therefore no accumulation in the fermenter (see Eqs. 3-6, part I). This gives linear equations which are easy to handle. However, we can adapt the model to non-
Table 3 Culture properties and parameter values for PHA production

\begin{tabular}{|c|c|}
\hline Reference & Durner et al. [20] \\
\hline Organism & Pseudomonas oleovorans \\
\hline Medium C-source/N-source & Octanoate/( $\left.\mathrm{NH}_{4}\right)_{2} \mathrm{SO}_{4}$ \\
\hline Number of datapoints & 50 \\
\hline $\mathrm{C} / \mathrm{N}$ ratio $(\mathrm{Cmol} / \mathrm{Nmol})$ & $1-33$ \\
\hline Dilution rates $\left(\mathrm{h}^{-1}\right)$ & $0.05,0.1,0.2,0.3,0.4$ \\
\hline$Y_{X N} \pm \mathrm{SD}\left(\mathrm{Cmol} \mathrm{Nmol}{ }^{-1} 1\right)$ & $4.0 \pm 0.8$ \\
\hline$q_{P, \max } \pm \mathrm{SD}\left(\mathrm{Cmol} \mathrm{Cmol}^{-1} \mathrm{~h}^{-1}\right)$ & $0.20 \pm 0.04$ \\
\hline$Y_{X S} \pm \mathrm{SD}\left(\mathrm{Cmol} \mathrm{Cmol}^{-1}\right)$ & $0.82 \pm 0.04$ \\
\hline$Y_{P S} \pm \mathrm{SD}\left(\mathrm{Cmol} \mathrm{Cmol}^{-1}\right)$ & $0.45 \pm 0.02$ \\
\hline$m_{\mathrm{S}} \pm \mathrm{SD}\left(\mathrm{Cmol} \mathrm{Cmol}^{-1} \mathrm{~h}^{-1}\right)$ & $0.11 \pm 0.02$ \\
\hline
\end{tabular}

$q_{P, \text { max }}$ maximum specific PHA production rate, $Y_{P S}$ yield of PHA on C-source

steady state conditions by including accumulation terms in the mass balances over the fermenter. We fitted this adapted model to data from a non-steady state culture [21]. We did not use Data set 13, because the glucose concentration in the feed is not given and could not be calculated because some vital information is missing. Instead, we used data from a recycling culture which was not in steady state [21]. This recycling culture is a continuous culture in which the biomass is retained while the medium is refreshed continuously. As a consequence, the biomass concentration in this culture increased in time. We determined parameter values from data of two recycling cultures with different $\mathrm{C} / \mathrm{N}$ ratios with the non-steady state version of the model, assuming there is no biomass in the outgoing liquid. Figure 7 shows the fit of the model to the data and the obtained parameter values. All graphs were calculated with the same parameter values except one parameter: we used different values of the yield of biomass on glucose for both cultures because we expected a difference in carbohydrate storage in both situations. The graphs show a good fit for all variables, and show that our model can indeed describe non-steady state cultures.

\section{Conclusions}

The model that was developed and partly validated in part I of this article [1] was further validated using 11 published data sets for chemostat cultures of oleaginous yeasts and one data set for PHA accumulating microorganisms. All data sets except one could be described well with the model, if a growth rate dependent yield of lipid-free cell mass on $\mathrm{N}$-source was incorporated (Eq. 27). One data set required another modification, i.e. the incorporation of a constant instead of a growth rate dependent minimum specific lipid production rate (Eq. 28). This shows that the 


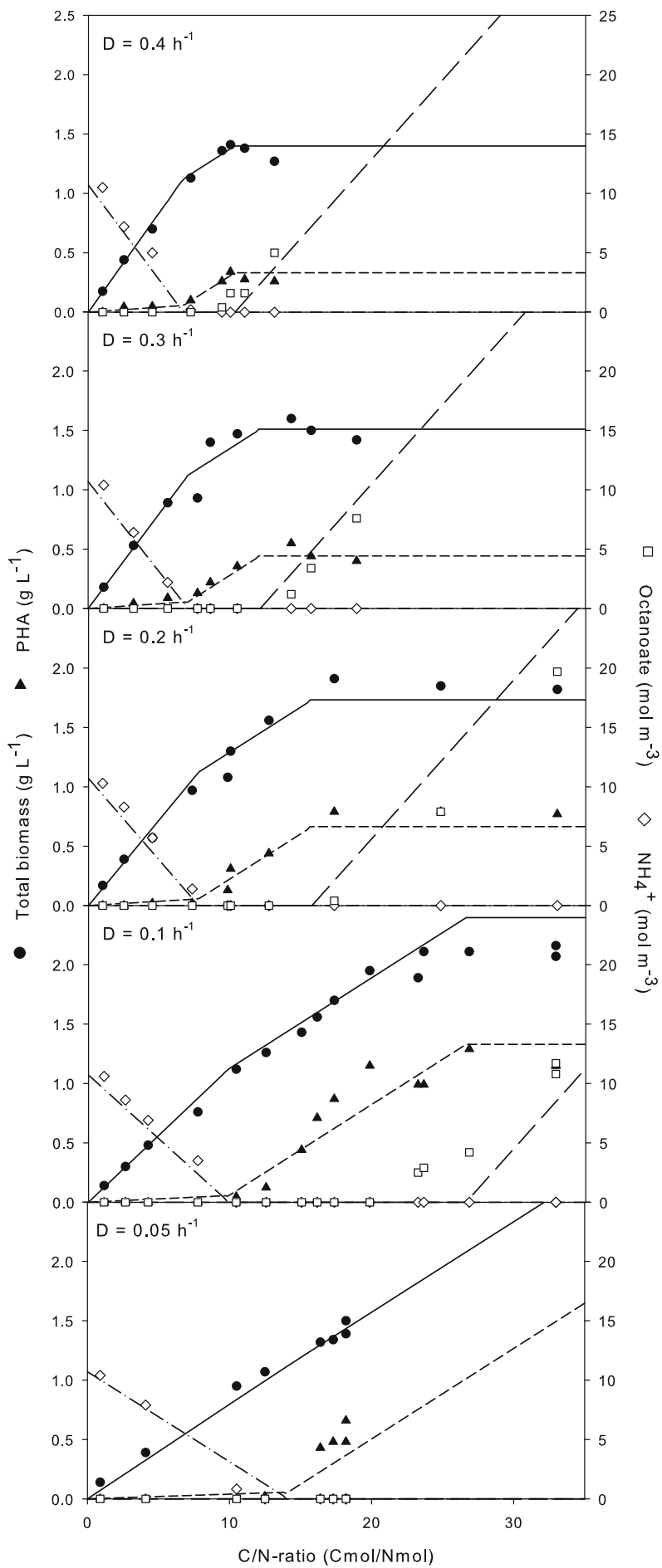

Fig. 6 Model (lines) and data points for PHA accumulating cultures of Pseudomonas oleovorans from Durner et al. [20]

main assumptions in the model are valid: (1) oleaginous yeasts and fungi give the highest priority to C-source utilization for maintenance, second priority to growth and third priority to lipid accumulation, and (2) oleaginous yeasts and fungi have a growth rate independent maximum specific lipid production rate. The maximum specific lipid

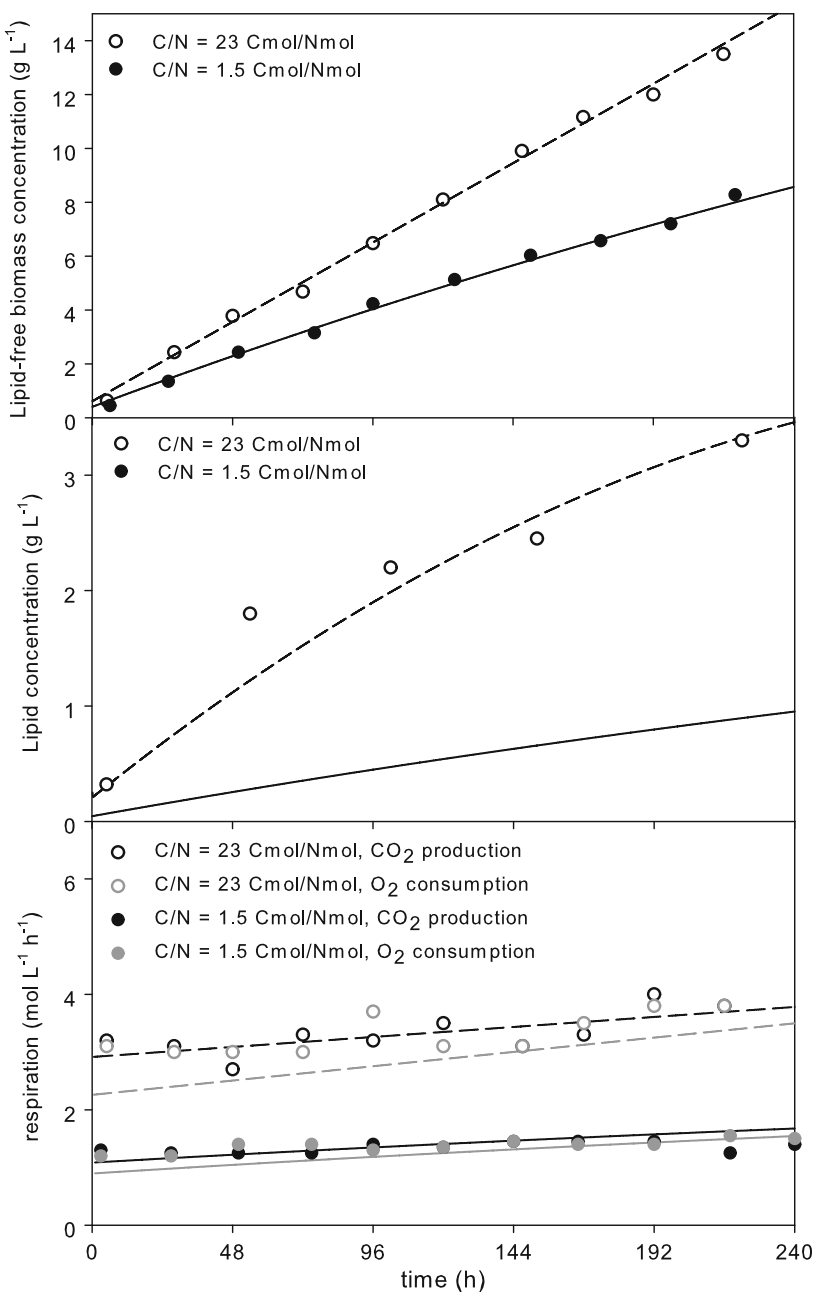

Fig. 7 Modeling of recycling cultures from Ykema et al. [21]. Parameter values found by non-linear fitting and iteration: $f_{L 0}=0.015 \mathrm{Cmol} \mathrm{Cmol}^{-1}, Y_{X N}=8.6 \mathrm{Cmol} / \mathrm{Nmol}, Y_{L S}=0.53 \mathrm{Cmol}$ $\mathrm{Cmol}^{-1}, m_{\mathrm{S}}=0.003 \mathrm{Cmol} \mathrm{Cmol}^{-1} \mathrm{~h}^{-1}, Y_{X S}=0.67 \mathrm{Cmol} \mathrm{Cmol}^{-1}$ for $\mathrm{C} / \mathrm{N}=1.5 \mathrm{Cmol} / \mathrm{Nmol}$ and $Y_{X S}=0.59 \mathrm{Cmol} \mathrm{Cmol}^{-1}$ for $\mathrm{C} / \mathrm{N}=23 \mathrm{Cmol} / \mathrm{Nmol}$

production rate was in most cases very close to the lipid production rate required for synthesis of the basal (membrane and functional) lipids in cells growing at their maximum specific growth rate. This indicates that the cells use the same pathway for lipid accumulation and for production of membrane and functional lipids, and that no special pathway is switched on for lipid accumulation in chemostat cultures. The assumption that the maximum specific lipid production rate is dictated by the maximum glucose uptake rate, postulated by Ykema et al. [2], was shown not to be correct for the tested data sets. Finally, the model proved also to be able to predict the production of PHA, another carbon-based storage product.

Acknowledgments This work was financially supported by the DEN program of SenterNovem under project number 2020-03-12-14- 
006. The authors would like to thank Sebastiaan Haemers and Fred van den End for their technical support.

Open Access This article is distributed under the terms of the Creative Commons Attribution Noncommercial License which permits any noncommercial use, distribution, and reproduction in any medium, provided the original author(s) and source are credited.

\section{References}

1. Meeuwse P, Tramper J, Rinzema A (2011) Modeling lipid accumulation in oleaginous fungi in chemostat cultures. I. Development and validation of a chemostat model for Umbelopsis isabellina. Bioproc Biosyst Eng. doi:10.1007/ s00449-011-0545-8

2. Ykema A, Verbree EC, Vanverseveld HW, Smit H (1986) Mathematical modeling of lipid production by oleaginous yeasts in continuous cultures. Antonie Van Leeuwenhoek 52:491-506

3. Hansson L, Dostalek M, Sorenby B (1989) Production of gammalinolenic acid by the fungus Mucor rouxii in fed-batch and continuous culture. Appl Microbiol Biotechnol 31:223-227

4. Song YD, Wynn JP, Li YH, Grantham D, Ratledge C (2001) A pre-genetic study of the isoforms of malic enzyme associated with lipid accumulation in Mucor circinelloides. Microbiology 147:1507-1515

5. Alvarez RM, Rodriguez B, Romano JM, Diaz AO, Gomez E, Miro D, Navarro L, Saura G, Garcia JL (1992) Lipid accumulation in Rhodotorula glutinis on sugar cane molasses in singlestage continuous culture. World J Microbiol Biotechnol 8:214-215

6. Brown BD, Hsu KH, Hammond EG, Glatz BA (1989) A relationship between growth and lipid accumulation in Candida curvata D. J Ferment Bioeng 68:344-352

7. Choi SY, Ryu DDY, Rhee JS (1982) Production of microbial lipid-effects of growth rate and oxygen on lipid synthesis and fatty acid composition of Rhodotorula gracilis. Biotechnol Bioeng 24:1165-1172

8. Evans CT, Ratledge C (1983) A comparison of the oleaginous yeast, Candida curvata, grown on different carbon sources in continuous and batch culture. Lipids 18:623-629
9. Gill CO, Hall MJ, Ratledge C (1977) Lipid accumulation in an oleaginous yeast (Candida 107) growing on glucose in singlestage continuous culture. Appl Environ Microbiol 33:231-239

10. Hansson L, Dostalek M (1986) Lipid formation by Cryptococcus albidus in nitrogen limited and in carbon limited chemostat cultures. Appl Microbiol Biotechnol 24:187-192

11. Hassan M, Blanc PJ, Granger LM, Pareilleux A, Goma G (1993) Lipid production by an unsaturated fatty acid auxotroph of the oleaginous yeast Apiotrichum curvatum grown in single-stage continuous culture. Appl Microbiol Biotechnol 40:483-488

12. Papanikolaou S, Aggelis G (2002) Lipid production by Yarrowia lipolytica growing on industrial glycerol in a single-stage continuous culture. Bioresour Technol 82:43-49

13. Ratledge C, Hall MJ (1979) Accumulation of lipid by Rhodotorula glutinis in continuous culture. Biotechnol Lett 1:115-120

14. Yoon SH, Rhee JA (1983) Quantitative physiology of Rhodotorula glutinis for microbial lipid production. Process Biochem $18: 2-4$

15. Somashekar D, Venkateshwaran G, Sambaiah K, Lokesh BR (2003) Effect of culture conditions on lipid and gamma-linolenic acid production by mucoraceous fungi. Process Biochem 38:1719-1724

16. Kendrick A, Ratledge C (1992) Lipid formation in the oleaginous mold entomophthora-exitalis grown in continuous cultureeffects of growth-rate, temperature and dissolved-oxygen tension on polyunsaturated fatty-acids. Appl Microbiol Biotechnol 37:18-22

17. Boulton CA, Ratledge C (1984) Cryptococcus terricolus, an oleaginous yeast re-appraised. Appl Microbiol Biotechnol 20:72-76

18. Ratledge C (1988) Biochemistry, stoichiometry, substrates and economics. In: Moreton RS (ed) Single cell oil. Longman Scientific and Technical, London, pp 33-70

19. Ratledge C, Wynn JP (2002) The biochemistry and molecular biology of lipid accumulation in oleaginous microorganisms. Adv Appl Microbiol 51:1-51

20. Durner R, Witholt B, Egli T (2000) Accumulation of poly[(R)-3hydroxyalkanoates] in Pseudomonas oleovorans during growth with octanoate in continuous culture at different dilution rates. Appl Environ Microbiol 66:3408-3414

21. Ykema A, Bakels RHA, Verwoert I, Smit H, Vanverseveld HW (1989) Growth yield, maintenance requirements, and lipid formation in the oleaginous yeast Apiotrichum curvatum. Biotechnol Bioeng 34:1268-1276 